\title{
Characterization, Acid Activation, and Bleaching Performance of Ibeshe Clay, Lagos, Nigeria
}

\author{
M. A. Usman, V. I. Ekwueme, T. O. Alaje, and A. O. Mohammed \\ Department of Chemical Engineering, University of Lagos, Lagos 101017, Nigeria \\ Correspondence should be addressed to M. A. Usman, mawwal04@yahoo.com
}

Received 23 December 2011; Accepted 11 January 2012

Academic Editor: P. Weisbecker

Copyright () 2012 M. A. Usman et al. This is an open access article distributed under the Creative Commons Attribution License, which permits unrestricted use, distribution, and reproduction in any medium, provided the original work is properly cited.

This paper investigated the possibility of using clay characterization as a major tool to predict its suitability for bleaching of vegetable oil, namely, palm oil. The clay sample collected from Ibeshe deposit was characterized by X-ray diffraction (XRD). The results of the XRD showed that the clay is composed of dioctahedral kaolinite and dickite, silica, ilmenite, and merlinite. The compositional analysis using atomic absorption spectroscopy (AAS) showed that the $\mathrm{Na}_{2} \mathrm{O}: \mathrm{CaO}$ ratio is 0.22 , a value less than one and indicative of the absence of bentonite which presence, just like montmorillonite, confers bleaching activity to clays. Furthermore, the $\mathrm{SiO}_{2}: \mathrm{Al}_{2} \mathrm{O}_{3}$ ratio of 1.12 (greater than one) is suggestive of a clay suitable not for bleaching but for zeolite development. Actual laboratory tests for bleaching performance evaluation confirmed the prediction above that the clay indeed has poor bleaching action as shown by percent colour reduction. The colour reduction for natural clay was $9.1 \%$. This value only increased to $27.3 \%$ after $3 \mathrm{M} \mathrm{HCl}$ activation, a value still very low for effective bleaching.

\section{Introduction}

The impurity load in vegetable oils can be reduced considerably by bleaching which is an adsorption process that utilizes clay as adsorbent. This may be naturally active or activated clays. Naturally active clays possess some bleaching activity and show a high adsorption capacity due to their high surface area. However, activated bleaching clays show a much higher activity [1]. Richardson [2] reported that activated bleaching earths are produced from clays which generally contain high proportions of montmorillonites through acid activation. Often times, clays exhibiting high natural bleaching power are not suitable for activation, and most clay used for activated clay manufacture is poor in natural bleaching ability. The correlation between chemical composition of clays and their adsorptive power is poor, and in fact poor adsorbents may have identical composition to those that are active. Therefore, the scientific basis for evaluating the bleaching potency of clays involves actual testing in the laboratory [3].

Adsorbents are activated by a mineral acid treatment resulting in the dealumination of the structure. A number of metal ions in the octahedral layer and impurities such as calcite are also removed by leaching with an inorganic acid at elevated temperatures [4]. In addition, the edges of the platelets are opened, and, as a result of all these changes, the pore diameters and the surface area increase. The pore diameters and the surface area with acid treatment range from 2.0 to $6.0 \mathrm{~nm}$ and 200 to $400 \mathrm{~m}^{2} / \mathrm{g}$, respectively, [4]. The higher the degree of activation, the higher the degree of cation substitution by the hydrogen ions of the acid in the clay structure:

$$
\text { Ca-bentonite }+2 \mathrm{H}^{+} \longrightarrow \text { H-bentonite }+\mathrm{Ca}^{2+} \text {. }
$$

Such treatment leads to leaching of aluminum, magnesium, and iron cations from the octahedral layer. Acid activation promotes catalytic activities by increasing the number of Bronsted and Lewis acid sites. During bleaching, the acidic properties will increase free fatty acids by splitting triglyceride molecules while the catalytic properties are responsible for the decomposition of peroxides [4].

Important bleaching or adsorption criteria are quantity of activated earth, dosage, time, mixing, temperature, and atmospheric pressure and vacuum [5]. The primary function of the bleaching process is to remove peroxides and secondary oxidation products. In addition pigments and any trace 
of gums and soaps from refining are removed [5]. The bleaching process is actually performed under steam/nitrogen blanket, vacuum, or in an open vessel. The vacuum provides advantages, like low temperature drying of oils, moisture removal from clay, and avoidance of contact with oxygen of the air [6]. This is because the activated clay may act as a catalyst for oxidation in the presence of oxygen at elevated temperatures. The resulting oxidation products lead to degeneration and short shelf life of the final products. Generally bleaching process is carried out at contact temperature in the range of $80-120^{\circ} \mathrm{C}$ and contact time ranging from 20-40 minutes under vacuum. Within this time, absorption of colouring matter on activated clay can be equilibrated under sufficient activation. The dosage of bleaching earth can vary depending on oil type. Chemical refining usually uses $0.5-2 \%$ on a weight basis. However, $2-4 \%$ bleaching earth can be used to meet final colour requirements [4]. Furthermore, the dosage of activated clay should be the minimum amount to effect removal of impurities as measured by peroxide reduction [5]. Generally oil loss results from oil lost to filter cake. Baranowsky et al. [1] reported that for oil retention, a typical value is approximately $40 \%$. This value can be reduced to $20-30 \%$ by a suitable procedure such as use of steam or nitrogen at the end of the filtration. They estimated that, for each $100 \mathrm{~kg}$ of fresh bleaching earth, $25-45 \mathrm{~kg}$ of oil are lost. Finer particle sizes of clays produce better bleaching results. However, filtration rate and oil retention can be affected adversely [4]. Therefore, efficient filtration, short filtration times, and minimization of oil retention on filter cake are necessary [7].

Bleaching clays normally contain $10-18 \%$ moisture. If the clay is completely dried prior to use, its structure collapses, causing reduction in the bleaching power because of decreased surface area. In addition to these, adsorptive capacity of acid activated clay is reduced if clay is added to hot oil. This is because the moisture in the clay is driven off too rapidly causing collapse of the clay structure. The acid activated earth should be added to dry, refined oil at $80^{\circ} \mathrm{C}$ under vacuum conditions and then rapidly brought up to working temperature and held at that temperature for enough time to provide maximal bleach [5].

This work is aimed at using characterization techniques to provide useful insight into the potential use for Ibeshe clay, particularly its bleaching performance, and to assess how well this prediction correlates with actual laboratory results.

\section{Materials and Methods}

2.1. Materials. The clay sample was taken from Ibeshe deposit, Epe Road, Ikorodu, Lagos. The crude palm oil was obtained locally from the Yaba market. Other materials used were hydrochloric acid, acetic acid, caustic soda, wij's reagent, sodium thiosulphate (all analytical grades reagents), distilled water, and phenolphthalein.

\subsection{Characterization}

2.2.1. X-Ray Diffraction. Analyses of metal oxide phases present in the raw sample as well as average crystallite sizes were determined by means of wide-angle X-ray analysis. Xray diffraction measurements were done on a Panalytical XPERT-PRO X-ray diffractometer with $\mathrm{Cu}-\mathrm{K} \alpha$ radiation of wavelength $1.541^{\circ} \mathrm{A}$ at $40 \mathrm{kV}$ and $30 \mathrm{~mA}$. The scan range was $10^{\circ}$ through $100^{\circ}$ at a scanning rate of 1 degree per minute and with a step size of $0.04^{\circ}$. Diffraction peaks of crystalline phases were compared with those of standard compounds.

2.2.2. Chemical Analysis. The quantities of $\mathrm{SiO}_{2}, \mathrm{Al}_{2} \mathrm{O}_{3}$, $\mathrm{Fe}_{2} \mathrm{O}_{3} \mathrm{CaO}, \mathrm{Na}_{2} \mathrm{O}, \mathrm{K}_{2} \mathrm{O}$, and $\mathrm{MgO}$ in the clay were determined using atomic absorption spectroscopy.

2.3. Activation of Clay. The activation method followed was an adaptation of that of Oboh et al. [3]. The clay sample was dried under the sun at an ambient temperature of $35^{\circ} \mathrm{C}$ to make them amenable to grinding. The clay sample was then reduced to fines by grinding with a laboratory mortar and pestle. The fines were sieved with a standard sieve 80 of 180 micrometer. Six concentrations of hydrochloric acid were prepared (0.0 M, 0.2 M, 0.5 M, 1.0 M, 2.0 M, and 3.0 M). $50 \mathrm{~g}$ of the clay sample was mixed with $250 \mathrm{~mL}$ each of the different concentrations of hydrochloric acid, and the mixture was heated at $105^{\circ} \mathrm{C}$ for 30 minutes. After slow cooling, the slurry was filtered and washed free of acid as indicated by a $\mathrm{pH}$ meter. The clay was then dried at a temperature of $110^{\circ} \mathrm{C}$ for 3 hours, ground using a mortar and pestle, sieved to 180 micrometer, and stored in desiccators.

2.4. Bleaching Studies. The crude palm oil was first degummed by adding $50 \mathrm{~mL}$ of $5 \% \mathrm{wt} / \mathrm{wt}$ acetic acid to $1000 \mathrm{~g}$ of oil at $80^{\circ} \mathrm{C}$ and stirred for 15 minutes. The mixture was centrifuged. Two layers were formed, oil and aqueous which contained phosphatides. The degummed oil was neutralized by adding $4 \mathrm{M}$ caustic soda and heating to a temperature of $110^{\circ} \mathrm{C}$ for 20 minutes. Two layers were formed after centrifuging, oil and soap. The brownish coloured soap was at the bottom while the oil was above it. $100 \mathrm{~g}$ of the neutralized oil was then mixed with $2 \mathrm{~g}$ of each concentration of hydrochloric acid at $110^{\circ} \mathrm{C}$ for 30 minutes. The bleached oil was cooled to $70^{\circ} \mathrm{C}$ and filtered. The activated clay had the colour of the oil but on heating returned to its former colour.

\subsection{Analysis}

2.5.1. Determination of Clay Moisture Content. $10 \mathrm{~g}$ of clay sample was used for moisture content determination. The mass of the clay was checked before and after drying. The clay was dried at $105^{\circ} \mathrm{C}$ for 15 minutes. The difference in mass was recorded as the moisture content.

2.5.2. Determination of Edible Oil Moisture Content. The edible oil moisture content was determined by the method described by Snell and Ettre [8].

2.5.3. Free Fatty Acid Content. The amount of free fatty acids was determined by simple titration using the method described by Snell and Ettre [8]. 
2.5.4. Peroxide Value (POV) Determination. Oil oxidation was determined by measuring the amount of peroxides. Peroxide value is most often expressed as milliequivalent of oxygen per kilogram of fat. Iodine is produced from potassium iodide solution by the peroxides present in oil and titrated against $0.01 \mathrm{M}$ sodium thiosulphate. Peroxide value was measured as reported by Snell and Ettre [8]. A blank test using $0.1 \mathrm{~mL}$ of $0.01 \mathrm{M}$ sodium thiosulphate was carried out and the peroxide value calculated as follows:

$$
\mathrm{PV}=\frac{\left(V_{s}-V_{b}\right) M \times 1000}{W},
$$

where $V_{s}$ : volume in $\mathrm{mL}$ of sodium thiosulphate solution of $0.01 \mathrm{M}$ used for the determination, $V_{b}$ : volume in $\mathrm{mL}$ of sodium thiosulphate solution of $0.01 \mathrm{M}$ used for the blank test, $W$ : weight in grams of the test portion, and $M$ : morality of sodium thiosulphate solution.

2.5.5. Determination of Iodine Value (IV). The iodine value of each sample was determined according to the EN ISO 3961 Wij's method [9]. Iodine monochloride (Wij's reagent) reacts with the double bond, and the excess reagent (as iodine) was titrated with sodium thiosulphate solution.

2.5.6. Assessment of Bleaching Performance. $5 \mathrm{~g}$ of clay samples, natural and activated, was mixed separately with $100 \mathrm{~mL}$ of crude palm oil and heated, with constant stirring, to $105^{\circ} \mathrm{C}$ and maintained for one hour. The slurry was separated by the use of a filter paper and the colour of the oil measured with a Lovibond Tintometer 12944. The reduction in colour was calculated as

$$
\begin{aligned}
& \text { Colour reduction }(\%) \\
& \quad=\frac{\text { crude oil colour }- \text { bleached oil colour }}{\text { crude oil colour }} \times 100 .
\end{aligned}
$$

2.5.7. Measurement of $p H .5 \mathrm{~g}$ of the clay sample was soaked in $100 \mathrm{~mL}$ distilled water for 12 hours. After thorough mixing, the $\mathrm{pH}$ of $25 \mathrm{~mL}$ of the solution was tested with a $\mathrm{pH}$ meter.

2.5.8. Oil Retention by Adsorbent. In the bleaching process, oil retention is required to ascertain the loss of oil due to its retention in the bleaching earth. Oil retention was calculated according to

Oil retention $(\%)$

$$
=\frac{W, \text { filter cake }-\left(W \mathrm{BE}-W \mathrm{H}_{2} 0\right)}{W, \text { filter cake }} \times 100,
$$

$W$ : weight in g, BE: bleaching earth [1].

2.5.9. Filtration Rate. This is the rate at which suspended solids are removed from a fluid by passing through a permeable fabric or porous bed of materials. The rate at which the palm oil passes through the filter leaving behind the clay was observed.
TABLE 1: Chemical composition of the Ibeshe clay sample.

\begin{tabular}{lccccccccc}
\hline Clay & $\mathrm{SiO}_{2}$ & $\mathrm{Al}_{2} \mathrm{O}_{3}$ & $\mathrm{MgO}$ & $\mathrm{K}_{2} \mathrm{O}$ & $\mathrm{Na}_{2} \mathrm{O}$ & $\mathrm{CaO}$ & $\mathrm{Fe}_{2} \mathrm{O}_{3}$ & $\begin{array}{c}\text { Loss on } \\
\text { ignition } \\
(\%)\end{array}$ \\
\hline $\begin{array}{l}\text { Raw } \\
\text { 3 M HCl } \\
\text { activated }\end{array}$ & 41.46 & 37.10 & 1.32 & 0.12 & 0.20 & 0.92 & 0.10 & 18.78 \\
\hline
\end{tabular}

\section{Results and Discussion}

3.1. Characterization. The compositional analyses of both the raw and activated clay are shown in Table 1.

The result showed that the ratio of $\mathrm{Na}_{2} \mathrm{O}$ to $\mathrm{CaO}$ was 0.22 , a value less than 1 and indicative of the absence of a swelling bentonite [10]. Similarly the amount of $\mathrm{SiO}_{2}$ and $\mathrm{Al}_{2} \mathrm{O}_{3}$ in the raw clay gives $\mathrm{SiO}_{2} / \mathrm{Al}_{2} \mathrm{O}_{3}$ ratio of 1.12 which was greater than 1 . This was well within the range of clays suitable for zeolite synthesis as suggested by Breck [11]. Thus, Ibeshe clay in Ikorodu, Lagos, Nigeria, may be appropriate as a starting raw material for zeolite catalyst development. Table 1 also shows that, except for $\mathrm{SiO}_{2}$ which recorded an increase in amount from $41.46 \%$ to $41.47 \%$, the amounts of all other constituents decreased after activation. This result was in conformity with the trend reported by Motlagh et al. [12]. Arfaoui et al. [13] rationalised this trend by stating that acid activation involved a partial destruction of the octahedral layer by dissolution of the $\mathrm{Al}^{3+}, \mathrm{Mg}^{2+}$, and $\mathrm{Fe}^{3+}$ cations.

The X-ray powdered diffraction pattern of the raw Ibeshe clay is shown in Figure 1, and Table 2 displays the pattern list. The study showed that this is mixed clay composed mainly of the silica, kaolinite group, with lesser amounts of Ilmenite and Merlinoite. The kaolinite group included the dioctahedral minerals kaolinite $\left[\mathrm{Al}_{2} \mathrm{Si}_{2} \mathrm{O}_{5}(\mathrm{OH})_{4}\right]$ and dickite $\left[\mathrm{Al}_{2} \mathrm{Si}_{2} \mathrm{O}_{5}(\mathrm{OH})_{4}\right]$. This result agrees well with that of AAS which showed the absence of bentonite. Furthermore, the XRD lends more credence to the claim of the presence of kaolinite in the clay, a fact that reinforces the suitability of Ibeshe clay for zeolite development.

3.2. Effect of Hydrochloric Acid Activation. The hydrochloric acid activation of the clay affects its physiochemical properties as shown in Table 3. Activation resulted in increase in acidity which showed a decrease in PH from 5.90 to 3.98 for the special case of raw and $3 \mathrm{M}$ hydrochloric acid activated clay. This is plausible given the substitution of the cations by the hydrogen ions of the acid. Acid activation caused an increase in moisture content to occur from $14.2 \%$ in raw clay to $17.4 \%$ in $3 \mathrm{M} \mathrm{HCl}$ activated clay, representing an increase of $3.2 \%$. The moisture content for the clay lies within 10 $18 \%$ recommended by Wiedermann [5] as being appropriate to ensure that the clay structure does not buckle and loses its adsorptive capacity. The greater the concentration of the acid used, the greater the bleaching performance of the clay. The effect of acid activation on oil retention increased markedly by $18 \%$, from $34 \%$ to $52 \%$ for raw and $3 \mathrm{M} \mathrm{HCl}$ activated clay, respectively. This is attributable to the fact that acid activation creates more void spaces through leaching of 
TABLE 2: XRD pattern list.

\begin{tabular}{lcccccc}
\hline Visible & Ref. code & Score & $\begin{array}{c}\text { Compound } \\
\text { name }\end{array}$ & Displ. [ ${ }^{\circ}$ 2Th] & Scale fac. & Chem. formula \\
\hline$*$ & $01-085-0865$ & 46 & á-SiO & 0.000 & 0.725 & $\mathrm{SiO}_{2}$ \\
$*$ & $00-058-2002$ & 28 & Dickite-2M1 & 0.000 & 0.115 & $\mathrm{Al}_{2} \mathrm{Si}_{2} \mathrm{O}_{5}(\mathrm{OH})_{4}$ \\
$*$ & $01-075-3756$ & 14 & Ilmenite & 0.000 & 0.061 & $\left(\mathrm{Ni}_{2} .5 \mathrm{Mg}_{5}\right) \mathrm{TiO}_{3}$ \\
$*$ & $00-029-0989$ & 15 & Merlinite & 0.000 & 0.112 & $\mathrm{~K}_{5} \mathrm{Ca}_{2}\left(\mathrm{Al}_{9} \mathrm{Si}_{23} .\right.$. \\
$*$ & $00-058-2030$ & 18 & Kaolinite-1Ad & 0.000 & 0.113 & $\mathrm{Al}_{2} \mathrm{Si}_{2} \mathrm{O}_{5}\left(\mathrm{OH}_{3}\right.$ \\
\hline
\end{tabular}

TABle 3: Physicochemical properties and beaching performance of raw and activated clay.

\begin{tabular}{lcccc}
\hline Clay & Moisture \% & $\mathrm{PH}$ & $\begin{array}{c}\text { Colour } \\
\text { reduction \% }\end{array}$ & $\begin{array}{c}\text { Oil } \\
\text { retention \% }\end{array}$ \\
\hline Raw clay & 14.2 & 5.90 & 9.091 & 34 \\
$3 \mathrm{M} \mathrm{HCl}$ act. clay & 17.4 & 3.98 & 27.273 & 52 \\
\hline
\end{tabular}

some components and cation-hydrogen ion exchange. There is probably some contribution from the moisture content which helps to firm up the clay structure, thereby preventing it from collapsing.

\subsection{Chemical Characteristics of Crude Palm Oil and Bleached} Oil with $3 \mathrm{M} \mathrm{HCl}$ Activated Clay. Figure 2 shows that there was a decrease in the values of POV and IV, from pretreatment values of $3.6 \mathrm{meq} / \mathrm{kg}$ and 52.66 to $2.8 \mathrm{meq} / \mathrm{kg}$ and 40.61 posttreatment figures. This represents a decrease of about $22.22 \%$ and $22.88 \%$, respectively, for POV and IV. The decrease in value is an indication that the clay showed some activity. For the iodine value, it shows a reduction in the degree of unsaturation, that is, the presence of compounds in the oil containing double bonds. Again this buttresses that the activated clay has some bleaching capacity. Furthermore, increases in the FFA and moisture content were recorded after activation, representing $34.57 \%$ and $11.50 \%$, respectively. The increase for FFA was contrary to the expected trend. However, this can be explained away by invoking the rationalization that the moisture in the raw oil might have caused the hydrolysis of palm oil triglycerides resulting in the formation of free fatty acids [14].

3.4. Bleaching Evaluation. The bleaching assessment for the natural clay as evident from Table 3 is indeed very poor with a colour reduction of $9.091 \%$. Upon activation with increasing $\mathrm{HCl}$ concentrations, there was increase in the Lovibond colour reduction from $9.091 \%$ to $27.275 \%$ as the concentration of the $\mathrm{HCl}$ used for activation varied from $0.2 \mathrm{M}$ to $3.0 \mathrm{M}$ as aptly displayed in Figure 3. This value is low considering that Oboh et al. [3] had reported colour reduction values as high as $90.70 \%$ after activation. The implication of this was that the Ibeshe clay neither possesses intrinsic bleaching capability nor is it amenable to improved performance through acid activation. The result of the laboratory test of the bleaching capability of the Ibeshe clay agrees well with the

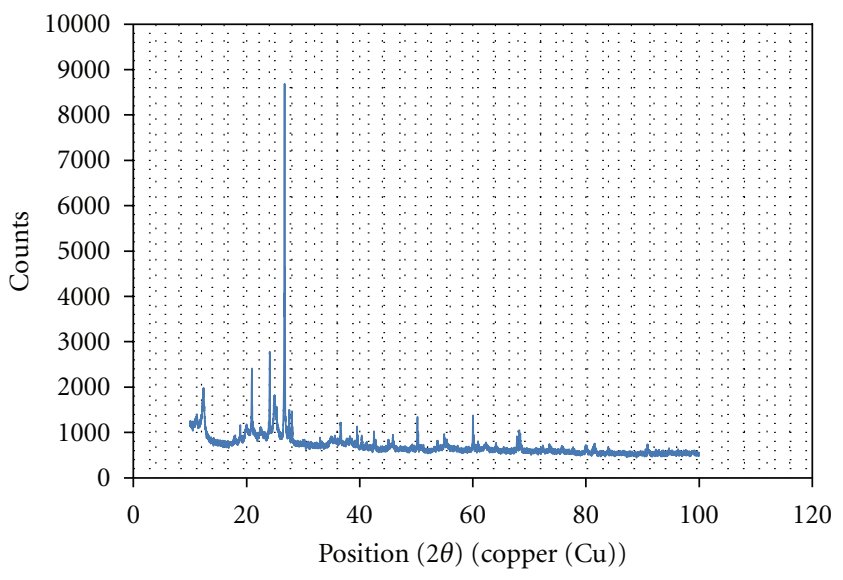

FIGURE 1: X-ray diffractogram of raw clay.

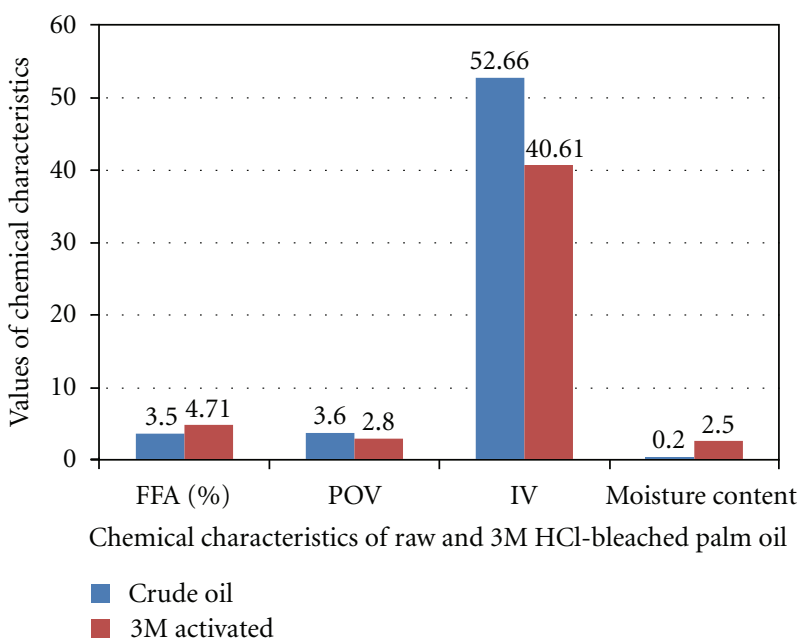

FIgURE 2: Chemical characteristics of raw and $3 \mathrm{M} \mathrm{HCl}$ bleached palm oil.

prediction, based on chemical and X-ray diffraction studies, that the clay is not suitable for bleaching of vegetable oil.

Figure 4 shows that there is no significant effect of size distribution on both the bleaching efficacy reported as percent colour reduction and percent oil retention. However, the trend of oil retention against mesh size follows the expected pattern increasing with decreasing particle size. 


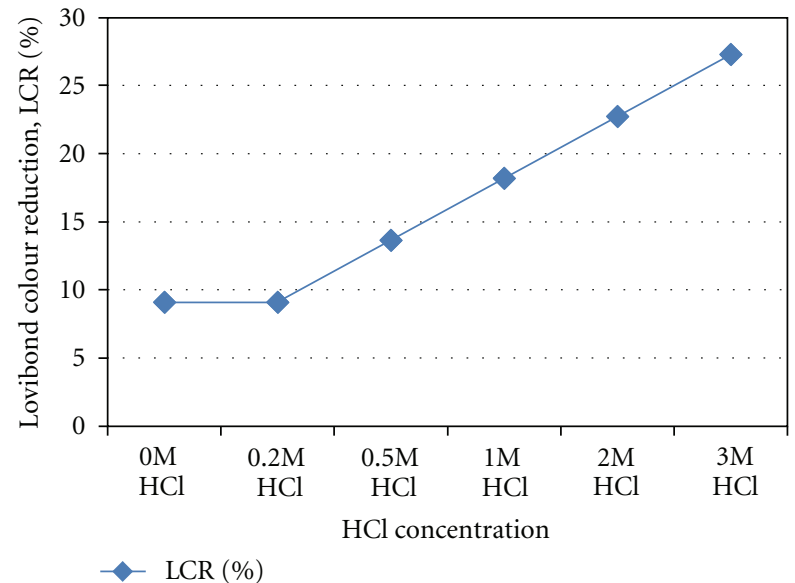

FIGURE 3: Variation of the Lovibond colour reduction (\%) of palm oil bleached with clay activated with different concentrations of $\mathrm{HCl}$.

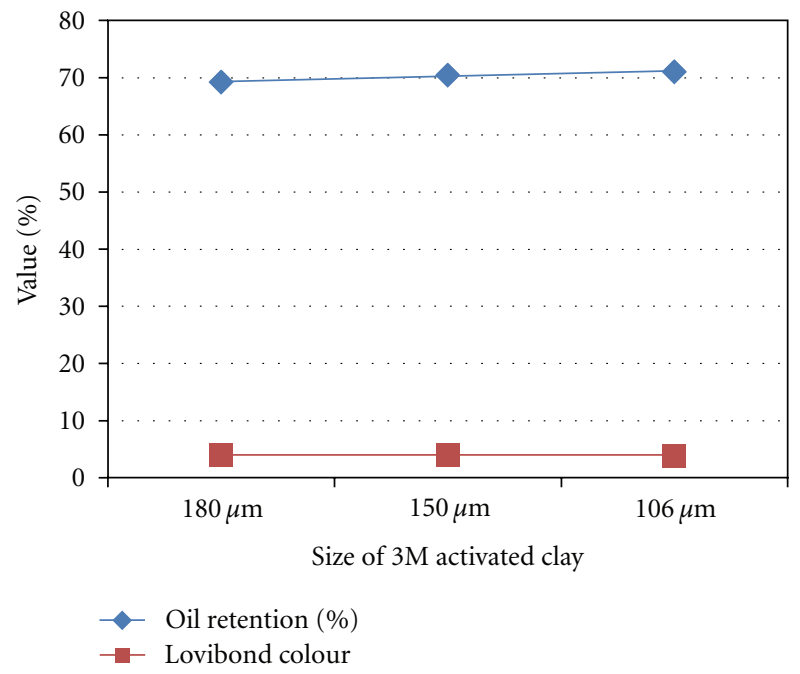

Figure 4: Oil retention (\%) and Lovibond colour (\%) of $3 \mathrm{M}$ activated clay.

\section{Conclusion}

Clay from Ibeshe, Ikorodu, Lagos state, Nigeria, consists of dioctahedral kaolinite and dickite, silica, ilmenite, and merlinite. The presence of the kaolinite and dickite was suggestive that the clay would possess poor bleaching capacity. The result of the chemical analysis with $\mathrm{SiO}_{2} / \mathrm{Al}_{2} \mathrm{O}_{3}$ ratio of 1.12 lent credence to the foregoing assertion, such ratio suggesting clay appropriate for zeolite development. Actual laboratory tests have confirmed the predictions made based on X-ray diffraction and chemical analyses that the clay is not suitable for vegetable oil refining.

This work showed that, through characterization, useful insight was gained into the appropriate use for the Ibeshe clay. Such insight helps to determine a priori the suitability or otherwise of a clay, not only for bleaching but also for catalytic (and sundry activities). Thus lengthy laboratory tests with the attendant costs can be eliminated. It is recommended that further studies be carried out to explore the potential of these clays for other industrial utilization, namely, zeolite production.

\section{References}

[1] K. Baranowsky, W. Beyer, G. Billek et al., "Technologies for industrial processing of fats and oils," European Journal of Lipid Science and Technology, vol. 103, pp. 505-551, 2001.

[2] L. L. Richardson, "Use of bleaching, clays, in processing edible oils," Journal of the American Oil Chemists' Society, vol. 55, no. 11, pp. 777-780, 1978.

[3] A. O. Oboh, O. C. Aworhi, and O. K. Agagu, "The use of Nigerian clays in vegetable oil refining: evaluation of some Nigerian clays as potential bleaching earths," Nigerian Food Journal, vol. 5, pp. 42-51, 1987.

[4] D. F. Valenzuela and S. P. De Souza, "Studies on the acid activation of Brazilian smectitic clays," Quimica Nova, vol. 24, no. 3, pp. 345-353, 2001.

[5] L. H. Wiedermann, "Degumming, refining and bleaching soybean oil," Journal of the American Oil Chemists' Society, vol. 58, no. 3, pp. 159-166, 1981.

[6] "Young's Corporation, User's Guide of Activated Clay," http:// www.youngscorp.com/.

[7] D. A. Morgan, D. B. Shaw, M. J. Sidebottom, T. C. Soon, and R. S. Taylor, "The function of bleaching earths in the processing of palm, palm kernel and coconut oils," Journal of the American Oil Chemists' Society, vol. 62, no. 2, pp. 292-299, 1985.

[8] F. D Snell and L. S. Ettre, Enclopedia of Industrial Chemical Analysis, Interscience, London, UK, 1969.

[9] ISO, "Animal and Vegetable Fats and Oils-Determination of Iodine Value," British Standard number 3961, 1999.

[10] Z. Wu, C. Li, X. Sun et al., "Characterization, acid activation and bleaching performance of bentonite from Xinjiang," Chinese Journal of Chemical Engineering, vol. 14, no. 2, pp. 253-258, 2006.

[11] D. W. Breck, Zeolite Molecular Sieve Structure, Chemistry and Uses, Wiley Inter Science, New York, NY, USA, 1974.

[12] K. M. M. Motlagh, A. Z. Rigi, and A. A. Yuzbashi, "To Evaluate an Acid Activated Bentonite from Khorasani (Iran) for Use as a Bleaching Clay, IUST International," Journal of Engineering Science, vol. 5, no. 2, pp. 83-87, 2008.

[13] S. Arfaoui, N. Frini-Srasra, and E. Srasra, "Modelling of the adsorption of the chromium ion by modified clays," Desalination, vol. 222, no. 1-3, pp. 474-481, 2008.

[14] D. D. Brooks, "Bleaching Factors that Affect the Oil Loss," in Proceedings of the PORIM International Palm Oil Congress (Chemistry and Technology), pp. 45-51, 1999. 

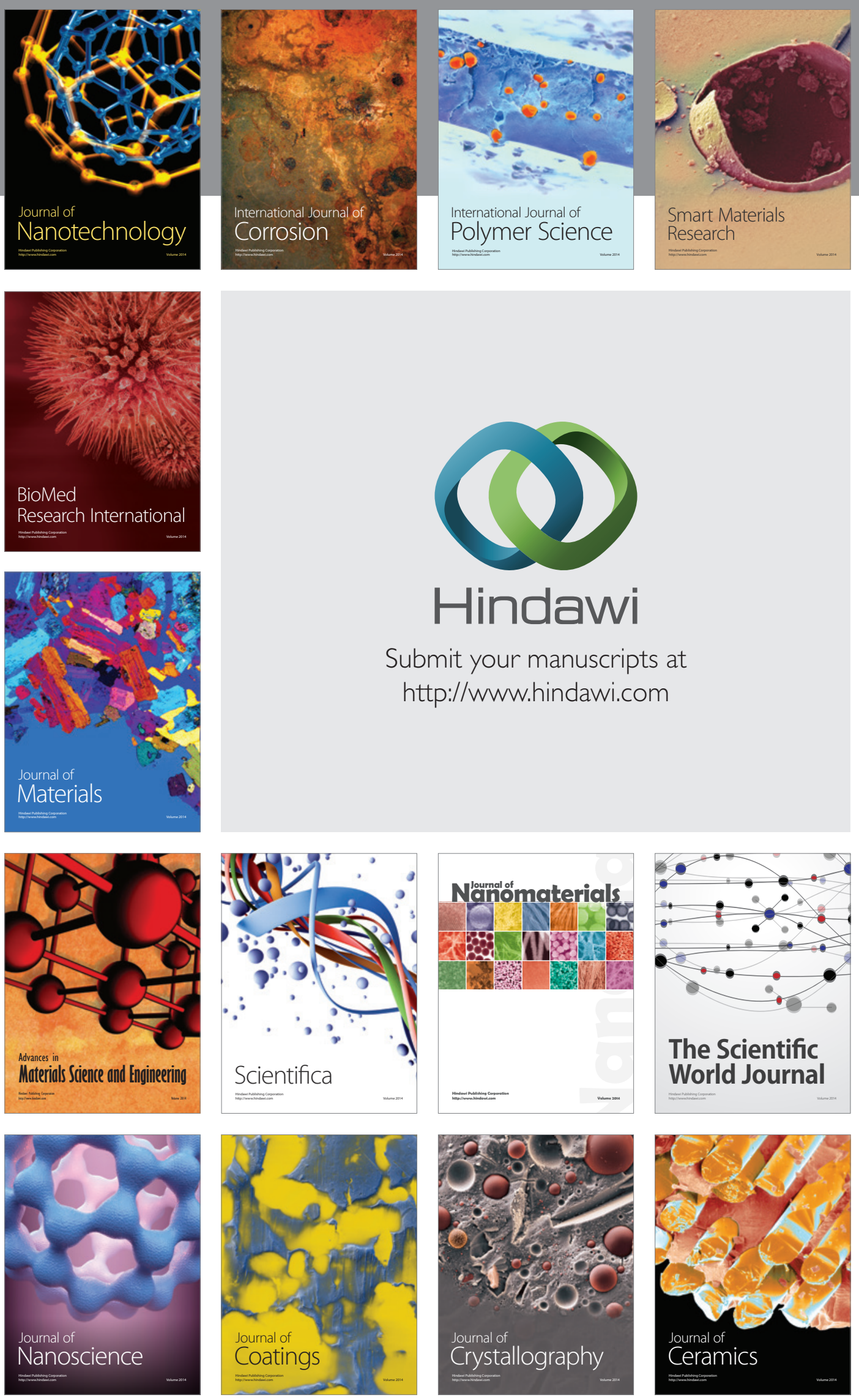

The Scientific World Journal

Submit your manuscripts at

http://www.hindawi.com

\section{World Journal}

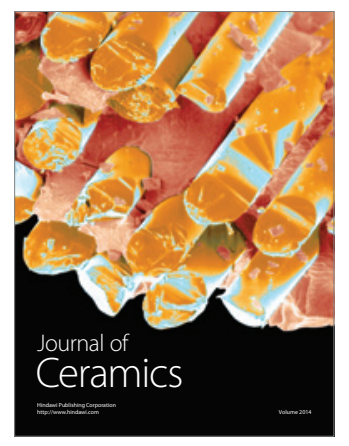

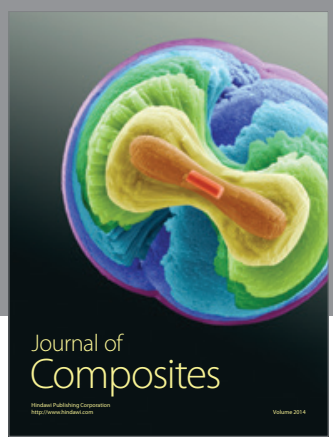
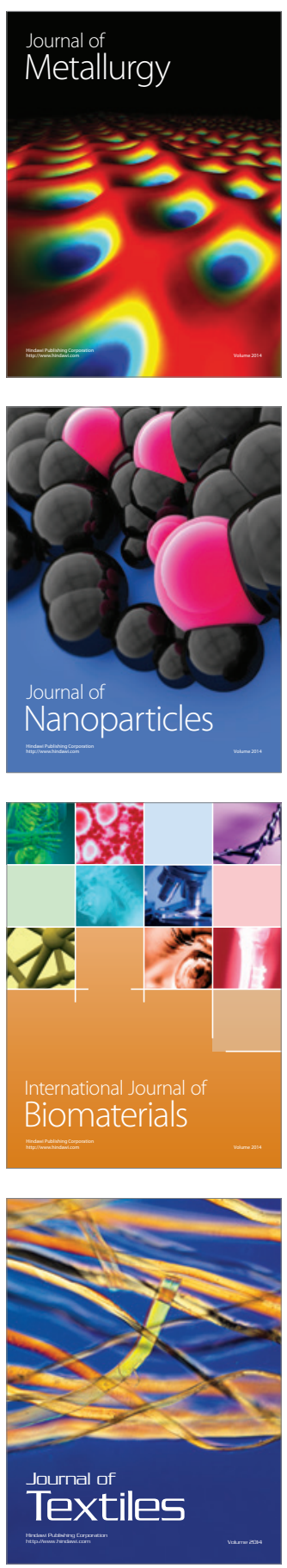